Research Article

\title{
A Study to Assess the Quality of Life among Children with Thalassemia and its Relationship with Selected Factors in Selected Hospitals of Delhi
}

\author{
Madhu Bains ${ }^{1}$, Kalpana Mandal $^{2}$ \\ ${ }^{1}$ Lecturer, College of Nursing, VMMC and Safdarjung Hospital, New Delhi, India. \\ ${ }^{2}$ Principal, Nightingale Institute of Nursing, Noida, Uttar Pradesh, India. \\ DOI: https://doi.org/10.24321/2349.2880.201911
}

I $\quad \mathbf{N} \quad \mathbf{F} \quad \mathbf{O}$

Corresponding Author:

Madhu Bains, College of Nursing, VMMC and

Safdarjung Hospital, New Delhi, India.

E-mail Id:

madhubains00@gmail.com

Orcid Id:

https://orcid.org/0000-0002-7951-448X

How to cite this article:

Bains M, Mandal K. A Study to Assess the Quality of Life among Children with Thalassemia and its Relationship with Selected Factors in Selected Hospitals of Delhi. Ind J Youth Adol Health 2019; 6(3): 1-7.

Date of Submission: 2020-02-28

Date of Acceptance: 2020-03-19
$\begin{array}{llllllll}\mathbf{A} & \mathbf{B} & \mathbf{S} & \mathbf{T} & \mathbf{R} & \mathbf{A} & \mathbf{C} & \mathbf{T}\end{array}$

Objectives: Assess the quality of life among children with Thalassemia and determine the association between quality of life of Thalassemia children with selected demographic factors.

Materials and Methods: The present study was aimed at assessing quality of life among thalassemia children using descriptive survey approach. A total of 100 Thalassemia children were selected by purposive sampling technique, from Safdarjung Hospital and Kalawati Saran Children Hospital OPD and Day Care Center. Structured interview schedule was used to assess quality of life among Thalassemia children. Analysis and interpretation of data for the present study were based on data collected through structured interview schedule from 100 children with Thalassemia by using both descriptive and inferential statistics based on objectives of the study.

Result: The data was collected, analyzed and interpreted in terms of the objectives. Descriptive and inferential statistics were utilized for the analysis of the data. The level of significance set for testing the association was 0.05 using chi-square test. The mean, median and standard deviation values were close to each other which indicate that group was homogenous. Mean=86.58, Median=87.5 and standard deviation of quality of life score was 10.95 .

Conclusion: The major findings of the study were, majority of children were having moderate quality of life and there was a significant association between quality of life of Thalassemia children and selected demographic variables.

Keywords: Quality of Life, Thalassemia, Thalassemia Children, Selected Demographic Factors 


\section{Introduction}

Among all the childhood diseases, hematological and hereditary diseases are most life-threatening disease conditions which affect in their early life. It affects upon birth, severely affecting their ability to survive on their own due to chronic anemia resulting from an inherited hemoglobin disorder. With currently available medical treatment, affected children have a substandard quality of life and a shortened life expectancy. The selective pressure that have made the Thalassemia so common is not known but is assumed to be related to the geographic distribution of Thalassemia.

Regular blood transfusions lead to iron accumulation in organs and may disrupt organ functions and/ or damage organs. Iron overload is the most common cause of the mortality and morbidity associated with thalassemia.

This vulnerable section undergo various types of health problems. They are at risk to normal growth development and survival therefore requires primary health care in children aiming at prevention of disease and promotion of health.

Quality of life is a subjective construct which varies with the population studied. It is generally conceptualized as a multidimensional construct made up of a number of independent domains including physical health, psychological well-being, social relationships, functional roles and subjective sense of life satisfaction. ${ }^{1,2,3,4}$

It is important to understand more about quality of life in pediatric population to evaluate and improve the care patients receive. Children with chronic physical illness exemplified thalassemia are vulnerable to emotional and behavioral problems. A better understanding of the factors associated with HRQOL among children and adolescents with thalassemia could have a direct effect on the development of more suitable clinical counseling, and social support programs to enhance treatment outcomes, especially in terms of HRQOL of these patients. ${ }^{4,5,6,7}$

\section{Objectives}

- Assess the quality of life among children with Thalassemia.

- Determine the association between quality of life of Thalassemia children with selected demographic factors.

\section{Materials and Methods}

The study was conducted using descriptive survey approach using purposive sampling technique.

\section{Study Settings}

This study was conducted at Safdarjung Hospital and Kalawati saran Children Hospital OPD and Day Care Center.

- $\quad$ Pilot study was conducted from 23rd December 2014 to 3rd January 2015.

- Final data collection was done from 23rd January to 28th February 2015.

\section{Sample Size}

For the study a total of 100 Thalassemia children were selected by purposive sampling technique.

\section{Inclusion Criteria}

- Children who are diagnosed to have Thalassemia disease.

- $\quad$ Between the age of 8-12 years.

- Who are seeking services in Kalawati Saran Children Hospital and Safdarjung Hospital OPD and Day care center during data collection?

- Who can understand English or Hindi and willing to participate in the study?

\section{Exclusion Criteria}

- $\quad$ Children and parents who are not willing to participate.

- Children with Thalassemia with other disease.

\section{Data Collection}

For this study the technique used for data collection was 'Interviewing' It permits a greater coverage of large groups within a short period. It is appropriate for the population understudy. Hence interview was considered the most appropriate tool for the data collection.

\section{Content Validity of the Tool}

For the content validity of the tool, a criteria rating scale was prepared which consist of items with three responses for rating against each criterion like Fully met the criteria, Mostly met the criteria, Partially met the criteria and with remark column for each criterion. The tool with rating scale was submitted to the nine expert from the field of Nursing, Education, Medicine for validation. There were $100 \%$ agreement on the tool.

\section{Reliability of the Tool}

Pre testing of the structured interview schedule was done on $27^{\text {th }}$ December 2014. The patients chosen were similar in characteristics to those of the population under study to check the clarity of the items, relevance and ambiguity. On an average, each interview of the child took 35-40 minutes to complete the whole tool. On the basis of responses, reliability of the tool was calculated.

The reliability of Health Related Quality Of Life was established by using Cronbach alpha formula. Its reliability was found to be $r=0.83$.

Thus, the tools was found to be reliable.

\section{Description of the Tool}

The structured interview schedule was selected for data collection. 
The tool consists of two sections:

- Section I: It consist of 18 items on demographic characteristics of the patients such as present age, gender, religion, educational attainment, family income, educational qualification of both mother and father, family income, duration of illness, HB level, frequency of blood transfusion and duration of treatment.

- Section II: Structured Quality of Life scale to elicit quality of life. It consists of total 34 questions.

\section{Description of Quality of Life Scale}

PQOL (Pediatric Quality of Life) inventory - it is a standardized tool prepared by World Health Organization. As per need of the study this tool was modified and consisted of 34 statements. The interview schedule on the Quality of Life Scale was categorized in the following sections or domains, with higher scores indicating poor health or a low level of function. Patients' answers were presented as a profile of scores calculated for each scale. ${ }^{7,8}$

- Physical Domain

- Independent Domain

- Psychological Domain

- Social Relationship

- Schooling

\section{Scoring Criteria for Quality of Life}

- Very Good Quality of Life=<34

- Good Quality of Life=35-71

- Moderate Quality of Life=72-102

- Poor Quality of Life=103-136

\section{Data Analysis}

Analysis and interpretation were done as per the objectives of the study. Descriptive and inferential statistics were used for the analysis of the data.

The data finding has been organized and presented under the following sections:

Section I: Findings of demographic characteristics of children with Thalassemia

Section II: Mean, Median and Standard Deviation of Quality of Life Scores of children

Section III: Findings related to association of QOL (quality of life) and selected demographic variables

\section{Section I: Findings of demographic characteristics of children with Thalassemia}

The data presented in Table 1, depicted that maximum number of subjects $32 \%$ were in the age group of 8 years and maximum of them were male $72 \%$ and only $28 \%$ were female. Most of them $63 \%$ were diagnosed with the disease at birth and only $37 \%$ were diagnosed after birth.

Most of the children 55\% were having blood transfusion every month. In terms of hemoglobin levels most of them $52 \%$ were having their $\mathrm{Hb}$ level between $8.1-11 \mathrm{mg} / \mathrm{dl}$.

Data also depict that most of the subjects $57 \%$ were receiving treatment since last one year.

Table I.Frequency and percentage distribution of children with thalassemia in terms of demographic characteristics

$(\mathrm{N}=100)$

\begin{tabular}{|c|c|c|}
\hline Sample characteristics & Frequency & Percentage \\
\hline \multicolumn{3}{|c|}{ Age } \\
\hline 8 years & 32 & 32 \\
\hline 9 years & 28 & 28 \\
\hline 10 years & 26 & 26 \\
\hline 11 years & 06 & 6 \\
\hline 12 years & 08 & 8 \\
\hline \multicolumn{3}{|c|}{ Gender } \\
\hline Male & 72 & 72 \\
\hline Female & 28 & 28 \\
\hline \multicolumn{3}{|c|}{ Age of diagnosis } \\
\hline At Birth & 63 & 63 \\
\hline After Birth & 37 & 37 \\
\hline \multicolumn{3}{|c|}{ Frequency of blood transfusion } \\
\hline Every Month & 55 & 55 \\
\hline Every second Month & 38 & 38 \\
\hline Every six Month & 07 & 7 \\
\hline \multicolumn{3}{|c|}{ HB level } \\
\hline Less than $8 \mathrm{mg} / \mathrm{dl}$ & 41 & 41 \\
\hline $\begin{array}{c}\text { Between } 8.1 \mathrm{mg} / \mathrm{dl} \text { to } \\
11 \mathrm{mg} / \mathrm{dl}\end{array}$ & 52 & 52 \\
\hline $11.1 \mathrm{mg} / \mathrm{dl}$ or more & 07 & 7 \\
\hline \multicolumn{3}{|c|}{ Duration of Treatment } \\
\hline Last one Year & 08 & 08 \\
\hline Last five Year & 57 & 57 \\
\hline $\begin{array}{c}\text { Five year or } \\
\text { More }\end{array}$ & 35 & 35 \\
\hline
\end{tabular}

Table 2.Frequency and percentage of samples as per their quality of life

$(\mathrm{N}=100)$

\begin{tabular}{|c|c|c|}
\hline Categories & Frequency & Percentage \\
\hline Very good $(>34)$ & 0 & 0 \\
\hline Good (35-71) & 6 & 6 \\
\hline Moderate (72-102) & 82 & 82 \\
\hline Poor (103-136) & 12 & 12 \\
\hline
\end{tabular}

Range of score is $34-136$. 


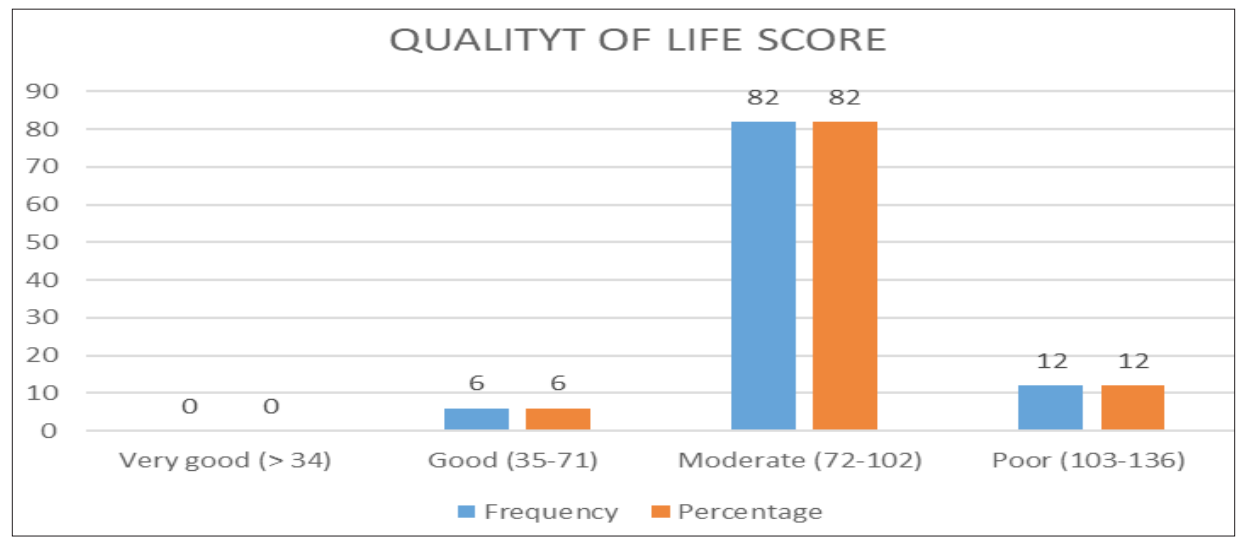

Figure I.Shows that the frequency and percentage of the interpretation of Quality of Life scores which indicates that maximum subjects $(82 \%)$ have moderate quality of life, $6 \%$ have good quality of life and about $12 \%$ were having poor quality of life.

\section{Section II: Mean, Median and Standard Deviation} of Quality of Life Scores of children

Table 3, shows mean, median and standard deviation values. The mean and median scores are close to each other which indicate that group was homogenous.

Table 3.Mean, median and standard deviation

\begin{tabular}{|c|c|c|c|}
\hline Variable & Mean & Median & S D \\
\hline Quality of Life & 86.58 & 87.5 & 10.95 \\
\hline
\end{tabular}

Section III: Findings related to association of QOL (quality of life) and selected demographic variables Table 4.Chi-square value showing association between quality of life and demographic variables

$(N=100)$

\begin{tabular}{|c|c|c|c|c|c|c|c|c|c|c|c|c|}
\hline \multirow{3}{*}{\multicolumn{2}{|c|}{ Variables }} & \multicolumn{8}{|c|}{ Health related quality of life } & \multirow{4}{*}{$\begin{array}{c}\begin{array}{c}N \\
(12)\end{array} \\
100 \\
32\end{array}$} & \multirow{3}{*}{$\begin{array}{l}x^{2} \text { Table Value } \\
\text { at } 0.05 \text { level }\end{array}$} & \multirow{3}{*}{ Chi- square test } \\
\hline & & \multicolumn{2}{|c|}{ Very good } & \multicolumn{2}{|c|}{ Good } & \multicolumn{2}{|c|}{ Average } & \multicolumn{2}{|c|}{ Poor } & & & \\
\hline & & $\mathbf{N}$ & $\%$ & $\mathbf{N}$ & $\%$ & $\mathrm{n}$ & $\%$ & $\mathbf{n}$ & $\%$ & & & \\
\hline \multirow{5}{*}{ Age } & 8 years & 0 & 0 & 4 & 4 & 26 & 26 & 2 & 2 & & \multirow{5}{*}{$\mathrm{df} 12=21.03$} & \multirow{5}{*}{$x^{2}=385.76(S)$} \\
\hline & 9 years & 0 & 0 & 0 & 0 & 22 & 22 & 6 & 6 & 28 & & \\
\hline & 10 years & 0 & 0 & 2 & 2 & 20 & 20 & 4 & 4 & 26 & & \\
\hline & 11 years & 0 & 0 & 0 & 0 & 6 & 6 & 0 & 0 & 6 & & \\
\hline & 12 years & 0 & 0 & 0 & 0 & 6 & 6 & 1 & 1 & 7 & & \\
\hline \multirow{2}{*}{ Gender } & Male & 0 & 0 & 1 & 1 & 59 & 59 & 12 & 12 & 72 & \multirow{2}{*}{ df $3=7.82$} & \multirow{2}{*}{$x^{2}=9.25(S)$} \\
\hline & Female & 0 & 0 & 4 & 4 & 21 & 21 & 3 & 3 & 28 & & \\
\hline \multirow{3}{*}{$\begin{array}{l}\text { Age of } \\
\text { diagnosis }\end{array}$} & Before Birth & 0 & 0 & 0 & 0 & 0 & 0 & 0 & 0 & 0 & \multirow{3}{*}{ df $6=12.59$} & \multirow{3}{*}{$x^{2}=1330.3(S)$} \\
\hline & At Birth & 0 & 0 & 6 & 6 & 52 & 52 & 5 & 5 & 63 & & \\
\hline & After Birth & 0 & 0 & 0 & 0 & 31 & 31 & 6 & 6 & 37 & & \\
\hline \multirow{4}{*}{$\begin{array}{l}\text { Frequency } \\
\text { of blood } \\
\text { transfusion }\end{array}$} & Every 15 days & 0 & 0 & 0 & 0 & 0 & 0 & 0 & 0 & 0 & \multirow{4}{*}{ df 9=16.92 } & \multirow{4}{*}{$x^{2}=244.13(S)$} \\
\hline & Every Month & 0 & 0 & 0 & 0 & 49 & 49 & 6 & 6 & 55 & & \\
\hline & $\begin{array}{l}\text { Every 2nd } \\
\text { Month }\end{array}$ & 0 & 0 & 6 & 6 & 31 & 31 & 1 & 1 & 38 & & \\
\hline & Every 6 Month & 0 & 0 & 0 & 0 & 1 & 1 & 6 & 6 & 7 & & \\
\hline \multirow{3}{*}{ HB level } & $\begin{array}{l}\text { Less than 8mg/ } \\
\text { dl }\end{array}$ & 0 & 0 & 1 & 1 & 35 & 3 & 5 & 5 & 41 & \multirow{3}{*}{ df $6=12.59$} & \multirow{3}{*}{$x^{2}=1015.65(S)$} \\
\hline & $8.1-11 \mathrm{mg} / \mathrm{dl}$ & 0 & 0 & 5 & 5 & 46 & 46 & 1 & 1 & 52 & & \\
\hline & $\begin{array}{c}11.1 \mathrm{md} / \mathrm{dl} \text { or } \\
\text { more }\end{array}$ & 0 & 0 & 0 & 0 & 1 & 1 & 6 & 6 & 7 & & \\
\hline
\end{tabular}




\begin{tabular}{|c|c|c|c|c|c|c|c|c|c|c|c|c|}
\hline \multirow{4}{*}{$\begin{array}{l}\text { Duration of } \\
\text { treatment }\end{array}$} & Since birth & 0 & 0 & 4 & 4 & 0 & 0 & 0 & 0 & 4 & \multirow{4}{*}{ df $9=16.92$} & \multirow{4}{*}{$x^{2}=917.49(S)$} \\
\hline & Last 1 year & 0 & 0 & 0 & 0 & 57 & 57 & 0 & 0 & 57 & & \\
\hline & Last 5 years & 0 & 0 & 0 & 0 & 3 & 3 & 5 & 5 & 8 & & \\
\hline & $\begin{array}{c}\text { More than } 5 \\
\text { years }\end{array}$ & 0 & 0 & 0 & 0 & 25 & 25 & 6 & 6 & 31 & & \\
\hline
\end{tabular}

Table 4, depicts that the chi square value between selected demographic variables and health related quality of life scores was found to be significant at 0.05 level of significance. Suggesting quality of life of Thalassemia were dependent on selected demographic variables. ${ }^{9}$

\section{Result}

The data was collected, analyzed and interpreted in terms of the objectives. Descriptive and inferential statistics were utilized for the analysis of the data. The level of significance set for testing the association was 0.05 using chi-square test. The part A consisted of 18 items on demographic characteristics of the patients, part-B comprises of pediatric quality of scale to elicit quality of life. It consists of total 34 question. Frequency and percentage distribution of children with Thalassemia to describe according to their demographic characteristics, mean, median and standard deviation of quality of life scores of children. Chi-square value to find association between quality of life with selected demographic factors. ${ }^{9}$

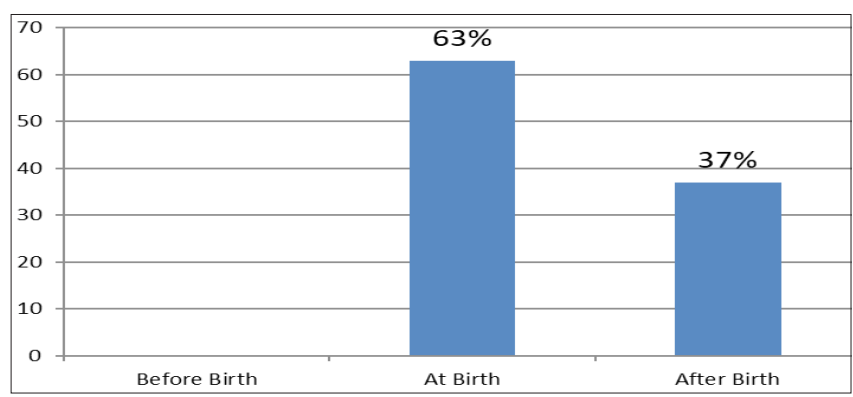

Figure 2.Bar showing distribution of children according to time of diagnosis of the disease

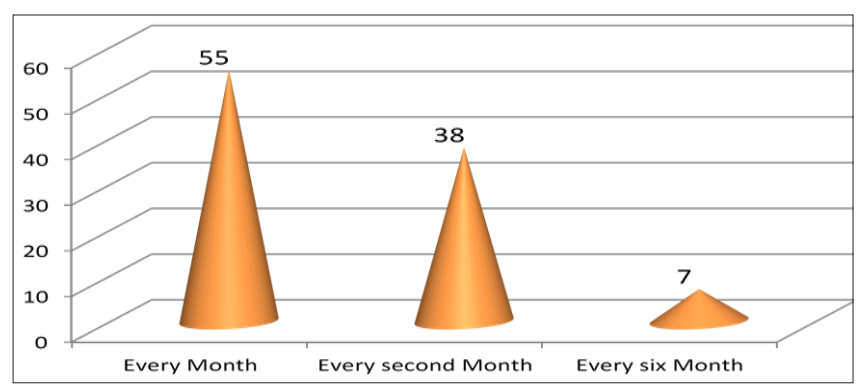

Figure 3.Cone showing distribution of children according to frequency of blood transfusion

Present study findings showed that there was significant association between quality of life of the children with present age, age of diagnosis, $\mathrm{Hb}$. level, frequency of blood transfusion and duration of treatment. The present study finding revealed that majority of children were male and with the age of 8 years, also the majority of Thalassemia children experience moderate quality of life.

\section{Discussion}

The present study was undertaken to assess the quality of life of Thalassemia children and its association with selected demographic variables from selected hospital of Delhi.

The result depict that maximum number of them were male $72 \%$ and only $28 \%$ were female. ${ }^{5}$ On contrary, others study showed there was non-statistically significant difference observed between male and female thalassemia patients. ${ }^{6}$ This difference in thalassemia patients (males more affected than female) is noteworthy and deserves further investigation considering thalassemia as a single gene disease transmitted by recessive mode of inheritance. ${ }^{7}$

In this study, it was observed that most of the patients (63\%) were diagnosed at birth (0-6 months) The above results are consistent with study conducted by Kirti Grow et al. which reported that $51 \%$ of patients were diagnosed with beta thalassemia major before 8 mo of age. ${ }^{10} \mathrm{~A}$ study conducted by Masyitah Sri Wahyuni et al. reported that more than half of the subjects were diagnosed with thalassemia at the age of less than $2 y$, although they had been anemic before the age of $2 .{ }^{11}$

The negative impact of the disease and its treatment can affect the quality of life in patients. In this study when the quality of life of thalassemic children was found to be average. Age at onset of anemia, age at first transfusion, irregular iron chelation therapy and low pre-transfusion hemoglobin levels were factors significantly affecting healthrelated quality of life. Various studies have reported that thalassemia pediatric had significantly lower health-related quality of life in all dimensions compared to their healthy counterparts. ${ }^{11}$

In the absence of adequate psychosocial intervention, chronically ill children may remain outside scope of formal education, something that in turn increases their isolation and misery which further affects the social life of the thalassemia patients. There is a need to develop a link between the patients, school officials, the family and the physician as they play an important role in helping children overcome this problem. 
As thalassemia is a type of anemia, improper oxygenation of cells can affect normal physical functions. This can lead to hindrance in patient's day to day activities. The chronic nature of the disease, regular visit to hospitals for blood transfusions and decreased physical functions may have an influence on the emotions of the patients.

In this study, we found that most of the patients had hemoglobin levels between mean pre-transfusion $\mathrm{Hb}$ in the range of $6-8 \mathrm{gm} / \mathrm{dl}$. The results of our study are comparable to the studies conducted by Masyitah Sri Wahyuni et al. and Mohaisen $\mathrm{H}$ Adaay et al. ${ }^{11}$ These results of low $\mathrm{Hb}$ among patients can be explained by the limited health education of the parents about the disease, so that, blood transfusion was used only when the patient showed clinical symptoms caused by severe anemia or simply just to sustain life.

In this study $55 \%$ of the thalassemic children were having blood transfusion every month for the afflicted patients to stay alive and $38 \%$ were getting blood transfusion every second month and only $7 \%$ were having blood transfusion every six month. The frequency of blood transfusion depends upon the age, severity of anemia, pre-transfusion hemoglobin level, blood type of the patient and availability of the blood.

\section{Conclusion}

Health-related quality of life of thalassemia children was found to be significantly lower than the other counterparts. Adverse transfusion reactions and complications were observed in our study. By increasing the awareness and knowledge levels of the parents, it can be helpful to get better care locally and thus improve the quality of life in thalassemia children It is important to identify and monitor transfusion-related adverse reactions so that we can improve the care given to the patients. Early detection of associated complications and adverse transfusion reactions in thalassemia patients would be quite helpful to reduce the burden of disease through preventive measures

\section{Nursing Education}

The gap between the existing and expected quality of life of Thalassemia children is one of the ways of setting priority in developing awareness program for population regarding Thalassemia.

In the existing Nursing curriculum experience in health teaching methods of teaching, it needs to be emphasized that the students need to have knowledge and skills in assessing the care of Thalassemia children in order to plan for providing care to children.

Sensitizing the nursing students about the implication of teaching concept for caring of the Thalassemia children can reduce children's morbidity and mortality.

The nursing education must aim to enable student nurses to gain skill required to be able to practice the psychological principles in setup where highly technological interventions are carried out.

\section{Nursing Practice}

The result of this study provides several implications for nursing practice:

Appropriate health care is an integral part of nursing practice. The incidence of Thalassemia disease morbidity and mortality is still high in developing countries. By proper nursing practice the incidences, morbidity and mortality among Thalassemia children can be reduced.

Clinical nurse must make people aware about the Thalassemia disease and its prevention as well as care of the children suffering from this disease.

The nursing personal working in hospital setting should supervise from time to time and identify the learning need of the parents to improve quality of life of Thalassemia children. This will update their ability to identify the learning need of parents and children and to teach them to take care of themselves.

\section{Nursing Administration}

The nurse administrator must have policy to acquire modern technological audio and video aids for continuing education program and symposium to be carried out for nurses in child care unit regarding various treatment modalities, blood transfusion techniques and iron chelation therapy, dose calculation, identifying complications etc. so that the knowledge can be utilized for better patient care.

Nurse administrator may plan and organize continuing education program for all categories of nursing personnel for updating current issues and trends in the care of children with Thalassemia.The nurse administrator may arrange education program for care givers of children with Thalassemia, so that the knowledge can be utilized for better patient care.

\section{Funding: None \\ Conflicts of Interest: None \\ References}

1. King CR, Hinds PS. Quality of Life, from nursing and patient perspective, Theory, Research, Practice. $1^{\text {st }}$ edition. Appleton and Lange, 2007.

2. Mohammad Abu S. Needs and concerns of Jordanian mothers with thalassemia children. Journal of American Science 2014; 10(1).

3. Ismail M, Yin Chun C, Mohd Yusoff $\mathrm{N}$ et al. Quality of life among thalassemia children. adolescent and their caregivers 2013; 42(3): 373-380.

4. Talsania S, Talsania N, Nayak $\mathrm{H}$ et al. A cross sectional study of thalassemia in Ahmedabad City, Gujarat 
(Hospital based). Healthline 2011; 2(1): 48-51.

5. Cunningham MJ, Macklin EA, Neufeld EJ. Complications of beta-thalassemia major in North America. Am Soc Haematol 2004; 104: 34-39.

6. Adaay MH, Al-Anzy MM, Al-Tikriti KA. Some observations on the occurrence of $\beta$-thalassemia in mosul. Iraq Joinerysoft Microsoft Pinpoint 2011; 9: 270-274.

7. Mehrnoosh Doroudchi, Ali Akbar Asadi Pooya. Thalassemia major and consanguinity in shiraz city, Iran. Turk J Hematol 2004; 21: 127-130.

8. Borhani F, Najafi MK, Rabori ED et al. The effect of family-centered empowerment model on quality of life of school-aged children with thalassemia major. Iran J Nurs Midwifery Res 2011; 16(4): 292-298.

9. Garrett HE. Statistics in Psychology and Education. $6^{\text {th }}$ edition. Paragon International Publishers, 2009.

10. Sattari M, Sheykhi D, Nikanfar A. The adverse effects of thalassemia treatments including blood transfusion and main pharmacological therapies. Pharm Sci 2013; 18: 199-204.

11. Giovanni Caocci, Fabio Efficace, Francesca Ciotti. Healthrelated quality of life in Middle Eastern children with beta-thalassemia. BMC Blood Disord 2012; 12: 1-7. 